Selected Papers from the 23rd International Radiocarbon Conference, Trondheim, Norway, 17-22 June, 2018 (C) 2019 by the Arizona Board of Regents on behalf of the University of Arizona. This is an Open Access article, distributed under the terms of the Creative Commons Attribution licence (http://creativecommons. org/licenses/by/4.0/), which permits unrestricted re-use, distribution, and reproduction in any medium, provided the original work is properly cited.

\title{
COMPOUND-SPECIFIC RADIOCARBON ANALYSIS OF ATMOSPHERIC METHANE: A NEW PRECONCENTRATION AND PURIFICATION SETUP
}

\author{
C Espic ${ }^{1,2} \cdot \mathrm{M} \mathrm{Liechti}^{1} \cdot \mathrm{M} \mathrm{Battaglia}^{1,2} \cdot \mathrm{D} \mathrm{Paul}^{3} \cdot \mathrm{T}^{\mathrm{R}}$ Rokmann $^{3} \cdot \mathrm{S} \mathrm{Szidat}^{1,2 *}$ \\ ${ }^{1}$ Department of Chemistry and Biochemistry, University of Bern, Bern, Switzerland \\ ${ }^{2}$ Oeschger Centre for Climate Change Research, University of Bern, Bern, Switzerland \\ ${ }^{3}$ Institute for Marine and Atmospheric Research (IMAU), Utrecht University, Utrecht, The Netherlands
}

\begin{abstract}
Methane contributes substantially to global warming as the second most important anthropogenic greenhouse gas. Radiocarbon $\left({ }^{14} \mathrm{C}\right)$ measurements of atmospheric methane can be used as a source apportionment tool, as they allow distinction between thermogenic and biogenic methane sources. However, these measurements remain scarce due to labor-intensive methods required. A new setup for the preparation of atmospheric methane samples for radiocarbon analysis is presented. The system combines a methane preconcentration line with a preparative gas chromatography technique to isolate pure methane samples for a compound-specific radiocarbon analysis. In order to minimize sample preparation time, we designed a simplified preconcentration line for the extraction of methane from $50 \mathrm{~L}$ atmospheric air, which corresponds to $50 \mu \mathrm{g} \mathrm{C}$ as required for a reliable ${ }^{14} \mathrm{C}$ analysis of methane-derived $\mathrm{CO}_{2}$ gas measurement with accelerator mass spectrometry (AMS). The system guarantees a quantitative extraction of methane from atmospheric air samples for ${ }^{14} \mathrm{C}$ analysis, with a good repeatability and a low processing blank. The setup was originally designed for the measurement of samples with low methane concentrations, but it can also be adapted to apportion sources from environmental compartments with high methane levels such as freshwaters or wetlands.
\end{abstract}

KEYWORDS: extraction, methane, preparative GC, radiocarbon, source apportionment.

\section{INTRODUCTION}

Since the beginning of the industrial revolution, the concentration of methane $\left(\mathrm{CH}_{4}\right)$ in the atmosphere has increased by a factor of 2.5 , which is mainly due to anthropogenic emissions (Dlugokencky et al. 2011). With a mole fraction higher than $1.8 \mathrm{ppm}, \mathrm{CH}_{4}$ is today the second most important anthropogenic greenhouse gas after $\mathrm{CO}_{2}$. Although the global budget of atmospheric $\mathrm{CH}_{4}$ is quite well constrained, individual sources remain poorly quantified and not well understood (Saunois et al. 2016). The spatial and temporal variability of $\mathrm{CH}_{4}$ emissions from natural sources are a major hindrance to forecasting and mitigation strategies (Bousquet et al. 2006; Saunois et al. 2016), and a warming climate could alter the strength of these emissions dramatically (Dean et al. 2018).

The sources of atmospheric $\mathrm{CH}_{4}$ are evaluated by top-down measurements and bottom-up inventories (e.g. Hiller et al. 2014; Jacob et al. 2016), but as a result of the natural variability of $\mathrm{CH}_{4}$ emissions, these approaches usually do not agree well (Nisbet and Weiss 2010). To improve this approach, stable and clumped isotopes of methane are also widely studied, because many $\mathrm{CH}_{4}$ sources have a specific isotopic signature (Quay et al. 1999; Stolper et al. 2015; Sapart et al. 2017).

The radiocarbon $\left({ }^{14} \mathrm{C}\right)$ content of atmospheric $\mathrm{CH}_{4}$ is of growing interest, since it can be used as a tool for a $\mathrm{CH}_{4}$ source apportionment (Wahlen et al. 1989; Lassey et al. 2007; Petrenko et al. 2008; Townsend-Small et al. 2012; Petrenko et al. 2017). Indeed, "contemporary" or "modern" $\mathrm{CH}_{4}$ sources (e.g. agriculture, biomass burning) contain present-day ${ }^{14} \mathrm{C}$ levels, whereas "old" or "fossil" $\mathrm{CH}_{4}$ sources (e.g. fossil fuels, geologic $\mathrm{CH}_{4}$ ) are ${ }^{14} \mathrm{C}$-free. Intermediate-age sources

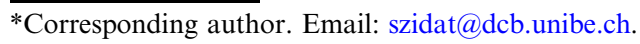


such as arctic lakes or peatlands can also be dated, providing valuable information about carbon dynamics in such environments (Zimov et al. 1997; Walter et al. 2006; Garnett et al. 2011). These ${ }^{14} \mathrm{C}$ measurements can be performed by accelerator mass spectrometry (AMS), but this task is challenging given the large amounts of $\mathrm{CH}_{4}$ required and its very low concentration in the atmosphere.

Methane is usually separated from other trace gases in a stepwise process (Lowe et al. 1991; Brenninkmeijer and Röckmann 1996; Röckmann 1998; Kessler and Reeburgh 2005; Petrenko et al. 2008; Pack et al. 2015): first $\mathrm{CO}_{2}$ is cryogenically removed, then $\mathrm{CO}$ is oxidized to $\mathrm{CO}_{2}$ and also cryogenically removed, before $\mathrm{CH}_{4}$ can finally be oxidized and isolated as $\mathrm{CO}_{2}$ as well. Alternatively, molecular sieves or soda lime are used to scrub $\mathrm{CO}_{2}$ (Palonen et al. 2017; Garnett et al. 2019). However, for these simplified processes, cross contamination of $\mathrm{CO}_{2}$ from one fraction to the next remains an issue difficult to monitor and overcome (Pack et al. 2015).

Some laboratories use a preparative gas chromatography technique to separate $\mathrm{CH}_{4}$ from $\mathrm{CO}_{2}$ and other trace gases. This technique has been applied for stable isotope measurements of $\mathrm{CH}_{4}$, where only small samples are necessary for such analysis (e.g. Miller et al. 2002; Bock et al. 2010; Brass and Röckmann 2010). It has also been used in combination with an AMS, for radiocarbon measurements of repeated injections of high concentration methane samples (McIntyre et al. 2013). Although a preparative gas chromatography technique warrants that pure $\mathrm{CH}_{4}$ is measured, its application for ${ }^{14} \mathrm{C}$ measurements of atmospheric $\mathrm{CH}_{4}$ is not straightforward as the required sample volumes are of several orders of magnitude larger for radiocarbon analysis.

Here, we present a new methane preconcentration and purification setup (MPPS) that allows the preparation of pure atmospheric $\mathrm{CH}_{4}$ samples for ${ }^{14} \mathrm{C}$ measurements. The system combines a methane preconcentration setup (PRECON) with a purification setup which applies preparative gas chromatography to obtain pure $\mathrm{CH}_{4}$ samples from the atmosphere (PURIF).

\section{METHODS}

\section{Goals and Strategy}

Our research aims at enabling the extraction of $\mathrm{CH}_{4}$ from various kinds of environments (e.g. atmosphere, fresh waters and wetlands) and performing ${ }^{14} \mathrm{C}$ measurements to deepen the knowledge of $\mathrm{CH}_{4}$ sources and the carbon cycle. The strategy adopted for the collection, preparation and radiocarbon measurements of environmental $\mathrm{CH}_{4}$ samples is shown in Figure 1.

The procedure can be divided in four main steps: field sampling, preconcentration, purification and ${ }^{14} \mathrm{C}$ measurement. As shown by the black dashed lines in Figure 1, the possibility to measure $\mathrm{CH}_{4}$ from aquatic and terrestrial environments will be implemented soon. However, the system has been developed and optimized for ${ }^{14} \mathrm{C}$ measurements of atmospheric $\mathrm{CH}_{4}$, as this task remains the biggest challenge given the low concentration of $\mathrm{CH}_{4}$ in air $(<2 \mathrm{ppm})$ and the overwhelming presence of $\mathrm{CO}_{2}(>400 \mathrm{ppm})$. First, $50-100 \mathrm{~L}$ of atmospheric air is collected in an aluminum bag which is brought to the lab, where it is connected to a methane preconcentration line (PRECON), to dramatically decrease the sample size by removing $\mathrm{CO}_{2}$ and most of the bulk air (i.e. $\mathrm{N}_{2}, \mathrm{O}_{2}$ and $\mathrm{Ar}$ ). The preconcentrated sample is then transferred to a $\mathrm{GC}$ column, where $\mathrm{CH}_{4}$ is chromatographically purified and subsequently trapped as pure $\mathrm{CH}_{4}$. The purity can be 


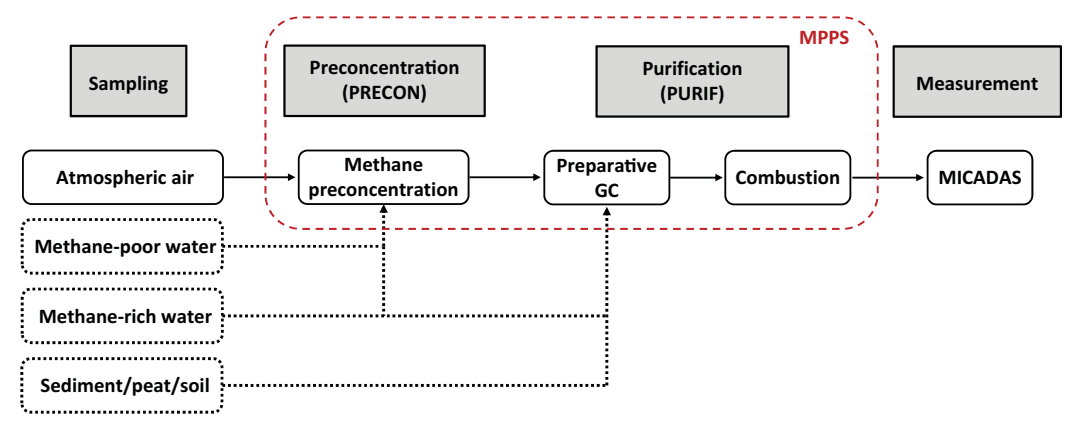

Figure 1 Strategy for ${ }^{14} \mathrm{CH}_{4}$ measurements. Red dashed box: methane preconcentration and purification setup (MPPS), which represents the essential part of this work. Black dotted line: connection of samples from other $\mathrm{CH}_{4}$ sources that will be measured in the future. (Please see electronic version for color figures.)

checked by re-injection of the trapped $\mathrm{CH}_{4}$ into the GC. It is then combusted to $\mathrm{CO}_{2}$, manometrically quantified and flame-sealed in a glass ampoule. Finally, the ${ }^{14} \mathrm{C}$ measurement of the $\mathrm{CH}_{4}$-derived $\mathrm{CO}_{2}$ is performed with a MICADAS AMS (Szidat et al. 2014).

The individual steps involved in a ${ }^{14} \mathrm{C}$ measurement of atmospheric $\mathrm{CH}_{4}$ are described in the following subsections, with a special emphasis on the PRECON and the PURIF analytical setups.

\section{Sampling}

It is necessary to extract $\mathrm{CH}_{4}$ from $50-100 \mathrm{~L}$ of air, as its concentrations are less than $2 \mathrm{ppm}$ in atmospheric background air and the target amount for reliable ${ }^{14} \mathrm{C}$ gas measurements is $50 \mu \mathrm{g}$ C. Therefore, atmospheric air samples are collected by pumping 50-100 L air (STP) into an aluminum bag (100 L PE-AL-PE, Tesseraux, Germany) using a small membrane pump (N838ANE, KNF, Germany).

\section{Methane Preconcentration Setup (PRECON)}

\section{Description}

A new methane preconcentration setup was developed in our laboratory. It facilitates a drastic reduction of the size of atmospheric air samples from 50-100 L down to 10-15 mL by removing most of the bulk air and $\mathrm{CO}_{2}$, while preserving the original $\mathrm{CH}_{4}$ content. This setup (see Figure 2a) is coupled to a methane purification setup (see Figure 2b), which will be described in the next section. The main components are three cryogenic traps cooled to liquid nitrogen temperature $\left(-196^{\circ} \mathrm{C}\right)$, of which the first (Russian doll trap, RDT) removes $\mathrm{CO}_{2}$, while the second (charcoal trap, CT1) and the third (CT2) allow two successive $\mathrm{CH}_{4}$ preconcentration steps.

The line consists of 1/4" stainless steel (SS) tubing with Swagelok connections (Swagelok, USA) and a central part between V2 and V7 made of $12 \mathrm{~mm}$ OD glass with grease-free Rotulex joints. These two parts are connected using Ultra-Torr (UT) fittings on the glass side and SS tube adapters on the metal side (Swagelok, USA). The gas flow rates in the line, all given in normal conditions $\left(1013 \mathrm{mbar}, 0^{\circ} \mathrm{C}\right)$, are regulated by two mass flow controllers $\mathrm{MFC1}$ (SLA5850S, 0-5 $\mathrm{L} \mathrm{min}^{-1}$, Brooks, USA) and MFC2 (SLA5850S, 0-150 $\mathrm{mL} \mathrm{min}^{-1}$, Brooks, 
(a)

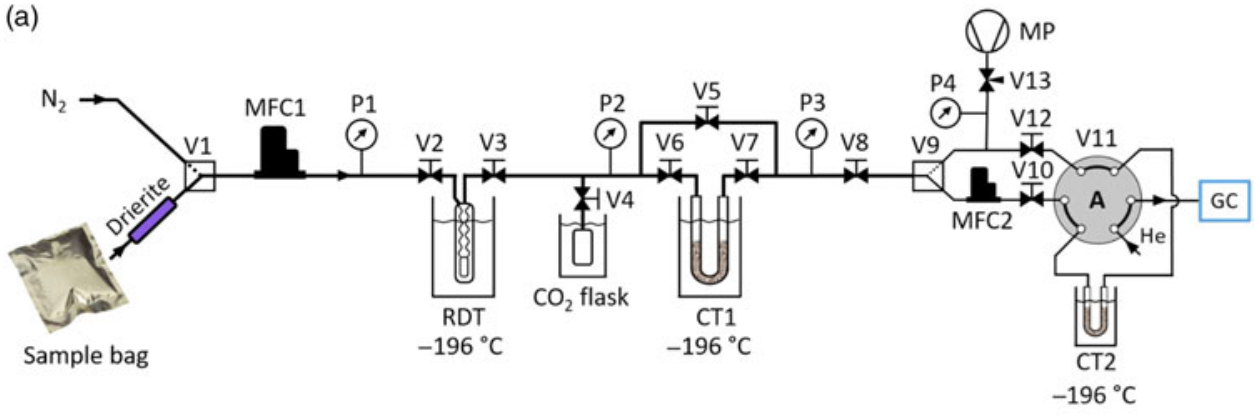

(b)

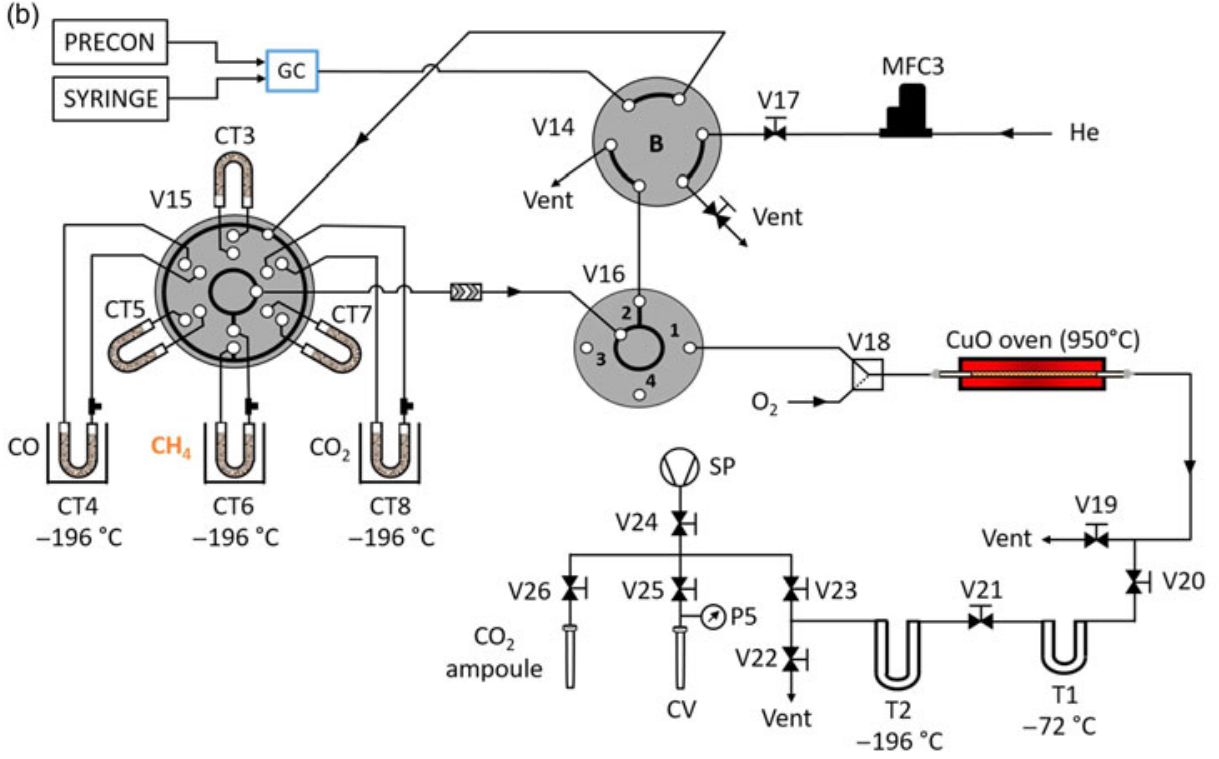

Figure 2 (a) Methane preconcentration setup (PRECON). The traps RDT, CT1 and CT2 are used for $\mathrm{CO}_{2}$ removal, first and second $\mathrm{CH}_{4}$ preconcentration steps, respectively. (b) Methane purification setup (PURIF), shown when trapping pure $\mathrm{CO}, \mathrm{CH}_{4}$ and $\mathrm{CO}_{2}$ provided from either a syringe injection or the PRECON.

USA). MFC1 and MFC2 regulate the flow for the first and second preconcentration step, respectively. The absolute pressure along the line is monitored by four pressure sensors $(\mathrm{P} 1-\mathrm{P} 3$ : PBMN Industrial Low Pressure, 0-2 bar; P4: PBMN flush, 0-2 bar, Baumer, Switzerland).

An aluminum bag (sample bag), which contains an atmospheric air sample collected in the field, is connected to the preconcentration line. The sample is dried in the trap "Drierite," a plastic tube $(24 \mathrm{~mm} I D, \mathrm{~L}=160 \mathrm{~mm})$ filled with $70 \mathrm{~g}$ of Drierite ${ }^{\mathrm{TM}}\left(\mathrm{CaSO}_{4}, 10-20 \mathrm{mesh}\right.$, Sigma-Aldrich, USA) which turns from blue to pink when it should be regenerated (60 min, $\left.210^{\circ} \mathrm{C}\right)$. V1 allows to switch to a nitrogen supply to clean the system $\left(\mathrm{N}_{2}\right.$, purity $=99.999 \%$, Carbagas, Switzerland).

RDT is a custom-made "Russian doll" glass trap of a concentric design, similar to the one described by Brenninkmeijer and Röckmann (1996). When immersed into liquid nitrogen, the undulations of its inner part and three nested glass fiber thimbles (Whatman $33 \times 94 \mathrm{~mm}$ 
and $25 \times 100 \mathrm{~mm}$, GE Healthcare, USA) at its bottom section ensure a very efficient trapping of $\mathrm{CO}_{2}$ and other lower volatility gases through the mechanisms of condensation and adsorption. This configuration allows an efficient removal of substantial amounts of $\mathrm{CO}_{2}$ at high flow rates. Atmospheric $\mathrm{CO}_{2}$, which has been scavenged from the air sample and trapped in RDT, can be recovered after the end of the preconcentration by cryogenically transferring it into the glass bottle " $\mathrm{CO}_{2}$ flask." An automated graphitization equipment (Němec et al. 2010) is then used for the production of solid targets for ${ }^{14} \mathrm{CO}_{2}$ measurements.

CT1 is a custom-made U-shaped glass trap (13 mm ID) filled with $12 \mathrm{~g}$ activated charcoal (Fluka 05112, grain size $0.3-0.5 \mathrm{~mm}, 0.41 \mathrm{~g} / \mathrm{cm}^{3}$, Sigma-Aldrich, USA). P2 and P3 are used to monitor the pressure drop across the trap and the stability of the system throughout the first preconcentration step. A bypass allows excluding this trap from the flow path when necessary.

The second $\mathrm{CH}_{4}$ preconcentration step is achieved in CT2, a custom-made 1/8" OD SS U-shaped trap $(2.16 \mathrm{~mm} \mathrm{ID}, \mathrm{L}=40 \mathrm{~cm})$ filled with $0.5 \mathrm{~g}$ charcoal. The trap is connected to the valve V11, an electrically actuated 2-position 6-port valve with $1 / 8^{\prime \prime}$ fittings (VICI, USA), which is used in "load" mode when $\mathrm{CH}_{4}$ is preconcentrated into CT2 (as shown in Figure 2a) or in "injection" mode when the sample in CT2 is transferred to the GC column of the PURIF.

The sample is pumped from the aluminum bag through the preconcentration line with a membrane pump MP (MZ 2C NT, Vacuubrand, Germany), which is well suited for the handling of high gas flow rates in the line. The pump has an ultimate vacuum of 7 mbar and is also used for cleaning purposes, as it can easily tolerate the removal of potential moisture in the line. Finally, V13 is a needle valve which allows to stop pumping the line gently when required.

\section{Procedure \\ Cleaning}

Before the preconcentration of an air sample, the line and particularly the traps are cleaned thoroughly to remove any contamination from the previous sample or from eventual leaks in the line. First, RDT is cleaned at $95^{\circ} \mathrm{C}$ (hot water bath) in a $\mathrm{N}_{2}$ flow of $1.5 \mathrm{~L} \mathrm{~min}^{-1}$ for $3 \mathrm{~min}$, to remove water vapor and other condensable gases that could remain adsorbed onto the glass fiber thimbles. In this step, CT1 is bypassed and the impurities are directly removed by the pump. As CT1 contains a significant amount of charcoal, care is taken to ensure that $\mathrm{CH}_{4}$ previously adsorbed is comprehensively eliminated. To do so, CT1 is heated to $95^{\circ} \mathrm{C}$, evacuated for $10 \mathrm{~min}$ and then flushed with $\mathrm{N}_{2}\left(20 \mathrm{~min}, 1.5 \mathrm{~L} \mathrm{~min}^{-1}\right)$. The trap is then pressurized to slightly above ambient pressure with $\mathrm{N}_{2}$ and closed. Finally, $\mathrm{CT} 2$ is heated to $95^{\circ} \mathrm{C}$ and evacuated for $3 \mathrm{~min}$, flushed for three additional minutes with $50 \mathrm{~mL} \mathrm{~min}^{-1} \mathrm{~N}_{2}$, pressurized to $\sim 1.2$ bar and closed.

\section{First Preconcentration}

$\mathrm{A} \mathrm{N}_{2}$ flow of $1.5 \mathrm{~L} \mathrm{~min}^{-1}$ is established in the line with CT1 bypassed and V9 positioned toward the pump. The sample bag is then opened and V1 is switched to connect the sample to the line. RDT is cooled to $-196^{\circ} \mathrm{C}$ to scrub $\mathrm{CO}_{2}$, and after $1 \mathrm{~min}, \mathrm{CT} 1$ is included into the flow path by cooling it to $-196^{\circ} \mathrm{C}$, opening its inlet (V6) and outlet (V7) and closing the bypass (V5). At that time, CT1 starts trapping $\mathrm{CH}_{4}$ and the flow integrator of $\mathrm{MFC1}$ is initiated to determine the total volume of air. During the $40 \mathrm{~min}$ of sample transfer at a flow rate of $1.5 \mathrm{~L} \mathrm{~min}^{-1}$, 
the pressures in the lines are monitored (P1, P2 and P3) to avoid a pressure rise due to a leak or a shortcoming of the pump that could trigger $\mathrm{O}_{2}$ condensation (Brenninkmeijer 1991). The pressure in the line is usually very stable, with typical values at gauges P2 and P3 of 205 mbar and 85 mbar, respectively. When the pressure at P1 drops below 200 mbar, indicating that the sample has been almost totally transferred to CT1, the inlets of RDT and CT1 are closed and V1 is switched to the $\mathrm{N}_{2}$ bottle. CT1 is evacuated until the pressure at its outlet is stable (i.e. P3 = 10-12 mbar). The liquid nitrogen bath is then replaced by a dry ice/ ethanol slurry $\left(-72^{\circ} \mathrm{C}\right)$ for $5 \mathrm{~min} 30 \mathrm{sec}$ to desorb and pump away excess air trapped together with $\mathrm{CH}_{4}$ into $\mathrm{CT} 1$. As shown below, there is no loss of $\mathrm{CH}_{4}$ when bulk air is removed from the trap at $-72^{\circ} \mathrm{C}$. V8 is then closed, and the dry ice/ethanol bath is replaced with an ambient temperature water bath to manometrically quantify the amount of gas still trapped in the enclosed volume delimited by V6 and V8. Typical sample volumes after the first preconcentration step are $80-100 \mathrm{~mL}$, which is too high to be directly transferred to the $\mathrm{GC}$ column for the $\mathrm{CH}_{4}$ purification.

\section{Second Preconcentration}

The second preconcentration step, which aims at further reducing the sample volume by removing excess air, is executed in a similar way and transfers the sample from CT1 to CT2. To do so, V9 is switched toward CT2 and the line until V8, including CT2, is evacuated. The valve to the pump V13 is then closed and CT2 is cooled to $-196^{\circ} \mathrm{C}$. CT1 is heated to $95^{\circ} \mathrm{C}$ to desorb $\mathrm{CH}_{4}$ together with excess air and all gases are then transferred to

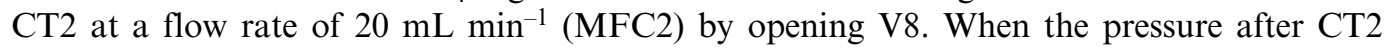
starts rising (P4), which indicates a breakthrough of air at CT2, V13 is opened to pump away excess air. When P3 drops below 50 mbar, CT1 is flushed with $20 \mathrm{~mL} \mathrm{~min}$ m $^{-1}$ through CT2 for 15 min to guarantee that all the $\mathrm{CH}_{4}$ adsorbed onto CT1 is carried to CT2. The transfer is stopped by closing V8 and CT2, still at $-196^{\circ} \mathrm{C}$, is evacuated for $1 \mathrm{~min}$. CT2 is then heated to $-72^{\circ} \mathrm{C}$ for exactly $1 \mathrm{~min} 30 \mathrm{sec}$ to desorb and remove excess air.

\section{Transfer to the PURIF}

The preconcentrated air sample, still trapped in CT2, is carried to the GC column by first switching V11 to position B (injection), which enables the He carrier gas from the GC to flush CT2 to the column. The dry ice/ethanol bath under CT2 is then removed, the trap is heated to $95^{\circ} \mathrm{C}$ to comprehensively desorb $\mathrm{CH}_{4}$ and other trapped gases and the $\mathrm{GC}$ run is started immediately afterwards.

\section{Methane Purification Setup (PURIF)}

\section{Description}

The methane purification setup (PURIF) is schematically shown in Figure 2 b. Small $(<10 \mathrm{~mL})$ $\mathrm{CH}_{4}$-containing gas mixtures are chromatographically purified and pure $\mathrm{CH}_{4}$ subfractions are recovered as $\mathrm{CH}_{4}$-derived $\mathrm{CO}_{2}$ in a glass ampoule. Although the setup mainly aims at preparing pure $\mathrm{CH}_{4}$ samples for subsequent ${ }^{14} \mathrm{C}$ analysis, this preparative $\mathrm{GC}$ technique allows even compound-specific radiocarbon analyses of $\mathrm{CH}_{4}, \mathrm{CO}, \mathrm{CO}_{2}$ and eventually $\mathrm{C}_{2} \mathrm{H}_{6}$. The gas sample is first chromatographically separated before pure $\mathrm{CH}_{4}$ is isolated in an individual trap. It is then transferred to a $\mathrm{CuO}$ oven where $\mathrm{CH}_{4}$ is converted into $\mathrm{CO}_{2}$, quantified manometrically and finally flame-sealed in a glass ampoule. The system can handle two different types of sample feed: (1) a manual syringe injection into the GC inlet (SYRINGE) and (2) an on-line injection of a preconcentrated air sample (PRECON). 
The GC (7890B, Agilent, USA) is equipped with a purged packed (PP) inlet, a packed column (ShinCarbon ST 80/100, $2 \mathrm{~mm}$ ID, L = $2 \mathrm{~m}$, Restek, USA) and a thermal conductivity detector (TCD). The PP inlet was modified such that the injection valve V11 of the PRECON was included into the flow path of the He carrier gas which feeds the inlet (see Figure 2a). The column is thus constantly flushed with $\mathrm{He}$ (purity $=99.999 \%$, Carbagas, Switzerland), and the flow is regulated by the electronic pneumatic control module of the GC. Hence, the option is kept to either perform a direct syringe injection of a gas mixture through the septum of the inlet (V11 in "load" mode, as shown in Figure 2a) or to transfer a preconcentrated sample from CT2 (PRECON) to the column (V11 in position "inject"). The column was chosen for its ability to handle large injection volumes at low bleeding and high efficiency of separating permanent gases and hydrocarbons. According to the physical properties of the packing material, the gases are mainly separated according to their volatility. Therefore, bulk air $\left(\mathrm{O}_{2}, \mathrm{~N}_{2}\right.$ and Ar) elutes first, followed by $\mathrm{CO}, \mathrm{CH}_{4}, \mathrm{CO}_{2}$ and finally trace gases of lower volatility. The oven is kept at $40^{\circ} \mathrm{C}$ for $4 \mathrm{~min}$ and is then heated to $250^{\circ} \mathrm{C}$ with a temperature ramp of $+10^{\circ} \mathrm{C} / \mathrm{min}$. The column is finally cleaned at $280^{\circ} \mathrm{C}$ for three additional minutes. The PP inlet is operated in constant pressure mode (20 psig), which causes a gradual decrease of the He carrier gas flow rate from $14 \mathrm{~mL} \mathrm{~min}^{-1}$ down to $9 \mathrm{~mL} \mathrm{~min}^{-1}$ as the temperature of the oven rises and the $\mathrm{He}$ viscosity increases consequently.

All the tubing is $1 / 8$ " SS with Swagelok fittings. The exhaust of the TCD is connected to V14, a 2-position 6-port valve (VICI, USA). When V14 is in position B, as shown in Figure 2b, the gases eluting from the column are carried to V15, a 6-position selector valve (EUTA2ST6MWE-CU, VICI, USA). The trapping consists of 6 identical custom-made $1 / 8$ " OD SS U-shaped traps $(2.16 \mathrm{~mm} \mathrm{ID,} \mathrm{L}=35 \mathrm{~cm})$, each of which filled with $0.4 \mathrm{~g}$ charcoal and connected to a port of V15. Although V15 was chosen for its small internal volume, intermediary traps are used to ensure a minimal cross contamination when V15 is switched from one collecting trap to the next. Each trap is also equipped with a septum injector nut (VICI, USA) holding a $6 \mathrm{~mm}$ septum (TCSD, Trajan, Australia) and connected to a union tee, allowing the collection of pure $\mathrm{CH}_{4}$ (in $\mathrm{He}$ ) aliquots with a syringe (Pressure-Lok Series A-2, 2 ml, VICI, USA).

V16 is a 4-position dead-end selector (EUTA-2SD4MWE-CU, VICI, USA). An external He supply (V14 in position A), flow-regulated by MFC3 (SLA5850S, 0-50 mL min ${ }^{-1}$, Brooks, USA) is used to either clean the 6 traps (V16 in position 2) or to transfer $\mathrm{CH}_{4}$ to the combustion oven (V16 in position 1). The methane combustion line consists of a quartz tube $(4 \mathrm{~mm}$ ID, $\mathrm{L}=40 \mathrm{~cm})$ filled with $5.4 \mathrm{~g}$ copper oxide wires $(0.5 \mathrm{~mm}$ diameter, Elementar, Germany) in its central part and connected on both ends to the SS line by means of UT fittings. The quartz tube stands in the middle of a custom-made combustion furnace heated to $950^{\circ} \mathrm{C}$.

The recovery part, where $\mathrm{CH}_{4}$-derived $\mathrm{CO}_{2}$ is quantified and sealed in an ampoule, is an adaptation of the THEODORE system described by Szidat et al. (2004). T1 and T2 are helicoidally-shaped $1 / 8^{\prime}$ SS lines cooled to $-72^{\circ} \mathrm{C}$ and $-196^{\circ} \mathrm{C}$ when trapping the combustion products $\mathrm{H}_{2} \mathrm{O}$ and $\mathrm{CO}_{2}$, respectively. The line is evacuated with a scroll pump SP (IDP-3, Agilent, USA) which allows to evacuate the line down to $1 \times 10^{-1} \mathrm{mbar}$. The amount of $\mathrm{CO}_{2}$ recovered after $\mathrm{CH}_{4}$ combustion is quantified with the pressure sensor P5 (PBMN Industrial Low Pressure, 0-1 bar, Baumer, Switzerland) in the calibrated volume 
(CV) of $7.94 \mathrm{~cm}^{3}$. The $\mathrm{CH}_{4}$-derived $\mathrm{CO}_{2}$ is finally flame-sealed into a glass ampoule (4 $\mathrm{mm} \mathrm{OD}$, $\mathrm{L}=6-7 \mathrm{~cm})$.

\section{Procedure}

When not in use, the recovery part remains evacuated to minimize contamination and to shorten the cleaning procedure preceding a sample processing. For similar reasons, CT3 to CT8 are always kept pressurized with He. The combustion oven is gradually heated to $950^{\circ} \mathrm{C}$ while flushing with $20 \mathrm{~mL} \mathrm{~min}{ }^{-1} \mathrm{He}$. Meanwhile, the GC column is baked out to remove any potential contamination and enable the TCD to reach a stable condition. The charcoal U-traps CT3 to CT8 are flushed one by one for $3 \mathrm{~min}$ each, and an overpressure ( 1.5 bar) is applied in each trap to prevent any external contamination. Just before the sample injection, the six traps are immersed into liquid nitrogen and are again individually pressurized to 1.5 bar with He. The valve V14 is then switched to position B and V16 to position 2 (see Figure $2 \mathrm{~b}$ ), so that the gases eluting from the GC column are transferred to the selected trap.

As stated above, the purification setup can either be used as a stand-alone unit, by directly injecting a gas mixture, or together with the PRECON. In the first case, the sample is injected with a syringe through the septum of the PP inlet and the GC run is started immediately after. When used together with the PRECON, the GC method is started just after heating the second preconcentration trap CT2 to $95^{\circ} \mathrm{C}$.

CT4, CT6 and CT8 are used to trap $\mathrm{CO}, \mathrm{CH}_{4}$ and $\mathrm{CO}_{2}$, respectively. The GC effluent is directed through the traps CT3, CT5 and CT7 between the peaks of the three target gases to avoid any cross contamination between the carbon-containing gases eluting from the column. The selector valve V15 is switched to the position of the chosen trap $30 \mathrm{~s}$ before the onset of the peak at the TCD and $45 \mathrm{~s}$ after the TCD signal has reached baseline to account for the transfer time between the detector and the traps (around $12 \mathrm{~s}$ ) and to ensure a comprehensive trapping of the pure subfractions. After the elution and adsorption of $\mathrm{CO}_{2}$ on CT8, V14 is switched to position A so that the GC flow is disconnected from the trapping part to avoid any low volatile gas eluting from the column to be adsorbed in a trap.

The six traps are heated to $95^{\circ} \mathrm{C}$ to desorb $\mathrm{CH}_{4}, \mathrm{CO}$ and $\mathrm{CO}_{2}$, the combustion line is flushed (35 $\left.\mathrm{mL} \min ^{-1} \mathrm{He}, 2 \mathrm{~min}\right)$ to a vent (V22) and $\mathrm{T} 1$ and $\mathrm{T} 2$ are cooled down to $-72^{\circ} \mathrm{C}$ and $-196^{\circ} \mathrm{C}$, respectively. CT6 is selected and $\mathrm{CH}_{4}$ is combusted in a He flow of $10 \mathrm{~mL} \mathrm{~min}^{-1}$ for $10 \mathrm{~min}$ and the $\mathrm{CH}_{4}$-derived $\mathrm{CO}_{2}$ is trapped in $\mathrm{T} 2$. When the combustion is completed, remaining $\mathrm{He}$ in $\mathrm{T} 2$ is pumped away and the $\mathrm{CH}_{4}$-derived $\mathrm{CO}_{2}$ is manometrically quantified in the calibrated volume $\mathrm{CV}$ before it is flame-sealed in a glass ampoule, ready for a ${ }^{14} \mathrm{C}-\mathrm{AMS}$ gas measurement.

\section{Methane Preconcentration and Purification Setup (MPPS)}

When the PRECON and the PURIF are used together for ${ }^{14} \mathrm{C}$ measurements of atmospheric $\mathrm{CH}_{4}$ samples, time can be saved by handling both setups simultaneously. During preconcentration of the sample, the PURIF is started up and cleaned. If a second sample needs to be processed, the cleaning of the PRECON is started (RDT, CT1 and CT2) while the first sample is purified in the GC column. A single preconcentration followed by a purification lasts $\sim 3 \mathrm{hr}$, two samples can be prepared for ${ }^{14} \mathrm{C}$ measurements in $\sim 5.5 \mathrm{hr}$ so that three samples may be handled in one working day. 


\section{Methane ${ }^{14} \mathrm{C}$ Measurement}

The $\mathrm{CH}_{4}$-derived $\mathrm{CO}_{2}$ ampoules are measured using the ampoule cracker of the gas handling system of the MICADAS at the University of Bern. The precision achieved during ${ }^{14} \mathrm{C}$ measurements of $\mathrm{CO}_{2}$ samples amounting $50-80 \mu \mathrm{g} \mathrm{C}$ is typically $1 \%$ for a modern sample. Two standards, a ${ }^{14} \mathrm{C}$-free $\mathrm{CO}_{2}$ blank and the NIST Standard Reference Material 4990C (Oxa-II, $\left.\mathrm{F}^{14} \mathrm{C}=1.3407 \pm 0.0005\right)$, are measured before and after the samples for blank subtraction, standard normalization and correction of isotopic fractionation (Szidat et al. 2014).

\section{RESULTS AND DISCUSSION}

\section{Optimization and Performance of the PRECON}

The PRECON was tested and optimized using a "pressurized air sample" from a commercially available pressurized air bottle (C017E5R, Druckluft, Carbagas, Switzerland), with measured concentrations of $426 \mathrm{ppm} \mathrm{CO}_{2}$ and $2.10 \mathrm{ppm} \mathrm{CH}_{4}$. It does contain neither water vapor nor $\mathrm{CO}$, as these gases were removed when atmospheric air was pressurized into the bottle. A cavity ring-down spectroscopy analyzer (G2401, PICARRO, USA) was connected to the exhaust of the membrane pump to control the concentrations of $\mathrm{CO}, \mathrm{CO}_{2}, \mathrm{CH}_{4}$ and $\mathrm{H}_{2} \mathrm{O}$ during the different steps of the procedure. Finally, the preconcentrated samples were transferred to the GC and the TCD was used to assess the performance of the preconcentration.

The RDT removes over $99.8 \% \mathrm{CO}_{2}$ for atmospheric air samples up to a total volume of $400 \mathrm{~L}$ without any $\mathrm{CO}_{2}$ breakthrough. As the preconcentrated sample is subsequently purified in the GC column, the scavenging of $\mathrm{CO}_{2}$ does not need to be quantitative. Hence, the usage of a single RDT is sufficient and simplifies the system operation compared to the setups from others, which apply multiple successive traps for this purpose (Wahlen et al. 1989; Brenninkmeijer and Röckmann 1996; Röckmann 1998; Kessler and Reeburgh 2005; Petrenko et al. 2008).

No measurable $\mathrm{CH}_{4}$ breakthrough $(<2 \%$ ) was observed in the first preconcentration trap (CT1, $12 \mathrm{~g}$ charcoal, $13 \mathrm{~mm}$ ID) for air samples up to $200 \mathrm{~L}$, corresponding to a total amount of $210 \mu \mathrm{g} \mathrm{C}\left(\mathrm{CH}_{4}\right)$ successively trapped, which is four times the targeted sample size. During the preconcentration of larger air volumes, the trapping efficiency drops gradually over time and reaches $50 \% \mathrm{CH}_{4}$ breakthrough after $430 \mathrm{~L}$ air. Thus, this trap should not be used for sample sizes over $200 \mathrm{~L}$, as isotopic fractionation may occur and would make eventual $\mathrm{CH}_{4}$ stable isotope measurements useless (Wahlen et al. 1989; Kessler and Reeburgh 2005).

The dimensions of the second preconcentration trap CT2 (0.5 g charcoal, $2.16 \mathrm{~mm}$ ID) were chosen as a downscaling of CT1 to further remove excess air while trapping the total amount of $\mathrm{CH}_{4}$ transferred from CT1. From an original air volume of $60 \mathrm{~L}$, the sample size is typically 80-100 mL after the first preconcentration step in CT1 and 10-15 mL after the second step in $\mathrm{CT} 2$, corresponding to successive $\mathrm{CH}_{4}$ enrichment factors of approximately 650 and 8 , respectively. Thus, $\mathrm{CH}_{4}$ is enriched to a concentration of $8-12 \%$ after the two preconcentration steps, which is in agreement with the values obtained by Bergamaschi et al. (1998) for a similar procedure. The enrichment factor is lower in CT2, which can be explained by the higher $\mathrm{O}_{2} / \mathrm{N}_{2}$ ratio in the sample in CT1 compared to the original ratio in atmospheric air. This $\mathrm{O}_{2}$ enrichment after the first preconcentration step is due to its lower volatility compared to $\mathrm{N}_{2}$, which causes a more efficient adsorption of $\mathrm{O}_{2}$ onto the charcoal. 
This discrimination over $\mathrm{N}_{2}$ is further enhanced in CT2, resulting in a larger proportion of the sample trapped in CT2. However, the slightly oversized CT2 prevents any $\mathrm{CH}_{4}$ loss during the preconcentration, and the final sample volume $(10-15 \mathrm{~mL})$ is still appropriate for a chromatographic separation in the GC column of the PURIF.

The performance of the PRECON was also evaluated by TCD measurements during the preconcentration of $60 \mathrm{~L}$ of the pressurized air sample, with known concentrations of $\mathrm{CO}$, $\mathrm{CH}_{4}$ and $\mathrm{CO}_{2}$. The results are detailed in the next section, together with the performance of the PURIF (see Figure 3 below).

\section{Optimization and Performance of the PURIF}

\section{Separation}

The main physical parameters that influence the quality of the chromatographic separation are the carrier gas flow rate and the temperature of the oven. The GC method optimization was carried out with a standard gas mixture $\left(79 \% \mathrm{~N}_{2}, 12 \% \mathrm{CO}_{2}, 5 \% \mathrm{O}_{2}, 2 \% \mathrm{CO}\right.$ and $\left.2 \% \mathrm{CH}_{4}\right)$ that contains higher concentrations of the main trace gases, as the TCD is not sensitive enough for the detection of low concentration compounds. The chromatogram of the syringe injection of 2 $\mathrm{mL}$ standard gas mixture, corresponding to approximately $20 \mu \mathrm{g} \mathrm{C}\left(\mathrm{CH}_{4}\right)$, is shown in Figure 3 . Methane is well separated from $\mathrm{CO}$ and $\mathrm{CO}_{2}$ even when using a temperature ramp to shorten the method.

An overload of the column causes a broadening and tailing of the peaks, as the column is not designed for such large gas volumes. The effect is enhanced when larger samples are injected, which causes further peak broadening and reduced retention times. This behavior does not affect the collection of pure $\mathrm{CH}_{4}$, as the peaks of $\mathrm{CO}, \mathrm{CH}_{4}$ and $\mathrm{CO}_{2}$ are still well separated. However, it causes a poor separation of $\mathrm{CO}$ from bulk air, which is partially counterbalanced by the low oven temperature of $40^{\circ} \mathrm{C}$ for the first $4 \mathrm{~min}$ of the run. Unfortunately, these two peaks start to overlap for samples bigger than $2 \mathrm{~mL}$. A longer column combined with a cooling of the oven could solve this issue if ${ }^{14} \mathrm{CO}$ measurements are of interest, but it would come at the cost of an extended time for the chromatographic separation and the column cleaning. As atmospheric CO is very low in concentration and hard to separate from ambient air due to a similar volatility to $\mathrm{O}_{2}$ (Brenninkmeijer 1993), the required modifications are currently not considered.

Figure 3 additionally shows the result of the preconcentration and chromatographic purification of $60 \mathrm{~L}$ of the pressurized air sample, when the PRECON and PURIF are jointly used. It should first be noticed that the retention times of the gases are 1-1.5 min longer compared to a direct injection. This is partly due to the sample transfer time between CT2 and the PP inlet, but also to a strongly reduced carrier gas flow rate when the preconcentrated sample in CT2 is heated, as it expands and creates an overpressure in the PP inlet. Fortunately, the shift of the retention times is reproducible and can be accounted for when the pure subfractions are collected in their respective traps. The sample volume after preconcentration is around $10-15 \mathrm{~mL}$, resulting in a strong broadening of the bulk air peak. The TCD signal slowly drops to the baseline after the elution of $\mathrm{O}_{2}$ and $\mathrm{N}_{2}$, which is mainly caused by the dead volumes in the line between CT2 and the PP inlet of the GC.

The PRECON greatly decreased the amount of $\mathrm{CO}_{2}$ from the air sample. However, the GC results show that the PURIF remains a mandatory step for getting reliable ${ }^{14} \mathrm{CH}_{4}$ results, as the 


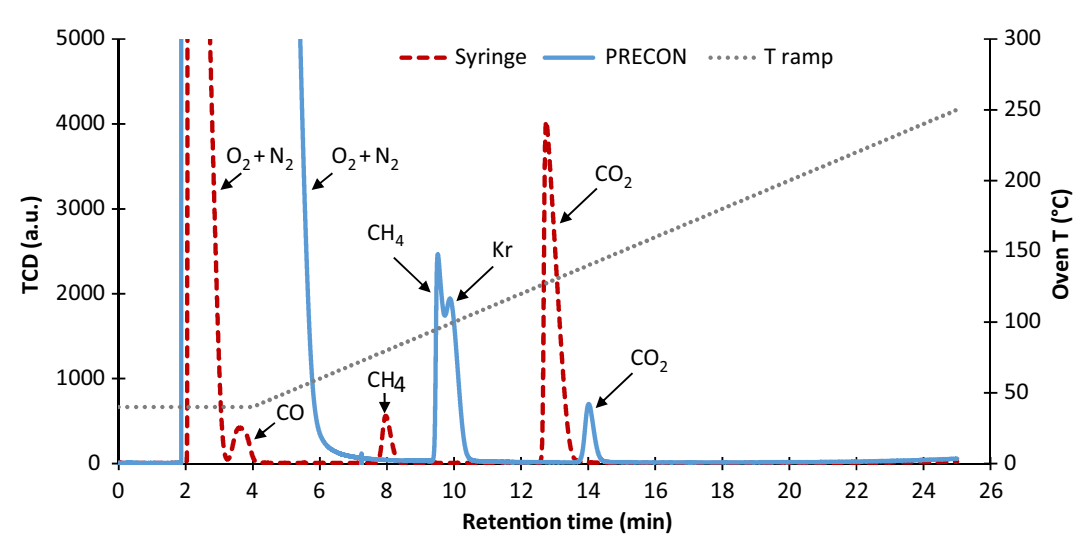

Figure 3 Chromatographic separation of a gas mixture. Dashed red line: injection into the PP inlet of $2 \mathrm{~mL}$ standard gas mixture $\left(79 \% \mathrm{~N}_{2}, 12 \% \mathrm{CO}_{2}, 5 \% \mathrm{O}_{2}, 2 \% \mathrm{CO}\right.$ and $\left.2 \% \mathrm{CH}_{4}\right)$. Blue line: on-line injection from the PRECON of the preconcentration of $60 \mathrm{~L}$ pressurized air sample (2.10 ppm $\left.\mathrm{CH}_{4}, 426 \mathrm{ppm} \mathrm{CO}_{2}\right)$. Grey dotted line: oven temperature program.

$\mathrm{CO}_{2}$ amount after preconcentration is $\sim 20 \%$ the amount of $\mathrm{CH}_{4}$. The residual $\mathrm{CO}_{2}$ originates from an incomplete scavenging of $\mathrm{CO}_{2}$ in RDT along with some $\mathrm{CO}_{2}$ production in $\mathrm{CT} 1$ when it is heated to $95^{\circ} \mathrm{C}$ (Bräunlich 2000).

Although $\mathrm{CH}_{4}$ is well separated from other carbon-containing gases, it unfortunately co-elutes with krypton $(\mathrm{Kr})$, a noble gas that shows concentrations of $\sim 1 \mathrm{ppm}$ in the atmosphere and similar physical properties with $\mathrm{CH}_{4}$. Since both separations in the charcoal traps of the PRECON and in the GC column are based on physical adsorption using carbon molecular sieves, $\mathrm{Kr}$ is preconcentrated together with $\mathrm{CH}_{4}$ in the PRECON and co-elutes with $\mathrm{CH}_{4}$. This issue was already documented by Schmitt et al. (2013). A full chromatographic separation may only be possible at the cost of cooling the GC oven or using a longer column, which would dramatically extend the whole procedure. As $\mathrm{CH}_{4}$ is ultimately combusted and recovered as $\mathrm{CO}_{2}$ in a glass ampoule, however, $\mathrm{Kr}$ is removed in this latter step. Consequently, co-eluting $\mathrm{Kr}$ impedes the ability to precisely quantify the amount of $\mathrm{CH}_{4}$ preconcentrated, but the manometric quantification of the $\mathrm{CH}_{4}$-derived $\mathrm{CO}_{2}$ can still be used to assess the yield and performance of the whole procedure involving PRECON and PURIF.

\section{Trapping}

Methane trapping efficiency after its chromatographic separation was measured by connection of the outlet of the $\mathrm{CH}_{4}$ trap (CT6) to the flame ionization detector (FID) of the GC, which is more sensitive to hydrocarbons than the TCD. Up to $2 \mathrm{~mL}_{\text {pure }} \mathrm{CH}_{4}$, which corresponds to an amount of $\sim 1000 \mu \mathrm{g} \mathrm{C}$, could be trapped at $-196^{\circ} \mathrm{C}$ for $50 \mathrm{~min}$, while the trap was flushed with a He flow rate of $35 \mathrm{~mL} \mathrm{~min}{ }^{-1}$ to the FID without any detectable breakthrough. This result yields to a trapping efficiency of $>99.99 \%$.

The $\mathrm{CH}_{4}$ trap is heated to $95^{\circ} \mathrm{C}$ when $\mathrm{CH}_{4}$ is transferred to the combustion oven. This temperature allows a comprehensive desorption of $\mathrm{CH}_{4}$ from the charcoal and thus prevents any isotopic fractionation (Bräunlich 2000). The traps CT4 and CT8 were also successfully tested for their ability to trap and desorb $\mathrm{CO}$ and $\mathrm{CO}_{2}$, respectively. 


\section{Combustion}

The choice of $\mathrm{CuO}$ as a catalyst for the conversion of $\mathrm{CH}_{4}$ to $\mathrm{CO}_{2}$ was based on several aspects: it is cheap, easy to use, regenerate or replace and shows a good oxidation efficiency of hydrocarbons without any need of an additional oxidant, which simplifies the isolation of pure $\mathrm{CH}_{4}$-derived $\mathrm{CO}_{2}$ (Dumke et al. 1989; Kessler and Reeburgh 2005). A long and thin quartz tube allows a comprehensive combustion of $\mathrm{CH}_{4}$ while the oven cleaning is facilitated, which minimizes cross contamination from a sample to the next. Methane combustion efficiency was assessed by connection of the outlet of T2 to the FID. As $\mathrm{CH}_{4}$ is not trapped in $\mathrm{T} 2$, an empty tube cooled to $-196^{\circ} \mathrm{C}$ without any adsorbent, a potential incomplete combustion of $\mathrm{CH}_{4}$ can be detected by the FID. Aiming at a time-efficient method, the highest $\mathrm{He}$ carrier flow granting a complete combustion of $\mathrm{CH}_{4}$ was sought. This is achieved at a flow rate of $10 \mathrm{~mL} \mathrm{~min}^{-1}$ and breakthroughs of $0.2 \%$ and $1.8 \%$ are observed for flow rates of $20 \mathrm{~mL} \mathrm{~min}{ }^{-1}$ and $35 \mathrm{~mL} \mathrm{~min}^{-1} \mathrm{He}$, respectively.

\section{Validation of the MPPS}

\section{Performance}

The constant contamination is a model of the procedural blank of a system (Brown and Southon 1997; Salazar et al 2015), which assumes that a constant amount of carbon with a fixed $\mathrm{F}^{14} \mathrm{C}$ value is added to the recovered $\mathrm{CH}_{4}$-derived $\mathrm{CO}_{2}$ when an air sample is preconcentrated and purified. It can be evaluated by processing $\mathrm{CH}_{4}$ standards of known mass and ${ }^{14} \mathrm{C}$ content through the whole procedure. We use a modern methane standard that was produced through the reduction of $\mathrm{CO}_{2}$, which was released by the combustion of tree leaves. The pure modern methane standard was measured with the MICADAS after combustion of $\mathrm{CH}_{4}$ to $\mathrm{CO}_{2}$ and shows a $\mathrm{F}^{14} \mathrm{C}$ of $1.024 \pm 0.003$, which is consistent with the results from the direct ${ }^{14} \mathrm{C}$ measurements of the $\mathrm{CH}_{4}$ with gas proportional counting (GPC) at the GPC Radiocarbon Lab at the Physics Institute of the University of Bern (Loosli et al. 1980). In order to ease the handling of small volumes, the modern methane standard was diluted to $10 \% \mathrm{CH}_{4}$ in $\mathrm{He}$. The $\mathrm{CH}_{4}$ contained in the standard gas mixture was used as a fossil $\mathrm{CH}_{4}$ standard, as it is totally depleted in ${ }^{14} \mathrm{CH}_{4}$ (i.e. $\mathrm{F}^{14} \mathrm{C}=0$ ). Different amounts of these two gases were injected with a septum injector nut at the preconcentration line before the RDT into a $\mathrm{N}_{2}$ flow of $60 \mathrm{~L}$ in total and the preconcentration and purification steps were performed as usually. The procedural blank (constant contamination) of the MPPS was determined to be $0.35 \pm 0.10 \mu \mathrm{g} \mathrm{C}$ with an $\mathrm{F}^{14} \mathrm{C}$ of $0.35 \pm 0.18$ (see Table 1 ). These values were calculated using the statistical model developed by Salazar et al. (2015). The cross contamination from the previous sample, which is $0.4 \pm 0.2 \%$, most likely originates from an imperfect cleaning of the charcoal traps.

The system repeatability was determined from several preconcentration, purification and ${ }^{14} \mathrm{CH}_{4}$ measurement of $60 \mathrm{~L}$ pressurized air sample (see Table 1). The MPPS exhibits a good repeatability, as the standard deviation of the $\mathrm{F}^{14} \mathrm{C}$ for all $\mathrm{CH}_{4}$ analyses of the pressurized air sample is 0.010 , which is comparable to the average $\mathrm{F}^{14} \mathrm{C}$ measurement uncertainty of a single analysis (0.012). To assess the system accuracy, repeated ${ }^{14} \mathrm{C}$ measurements of the modern methane standard that was processed through the MPPS were compared to the modern methane standard $\mathrm{F}^{14} \mathrm{C}$ reference value. The results, presented in Table 1, show that the mean $\mathrm{F}^{14} \mathrm{C}$ from the repeated measurements $\left(\mathrm{F}^{14} \mathrm{C}=1.018 \pm 0.008\right)$ is statistically indistinguishable from the reference value $\left(\mathrm{F}^{14} \mathrm{C}=1.024 \pm 0.003\right)$. The overall yield of the setup was calculated from the comparison of the amount of $\mathrm{CH}_{4}$-derived $\mathrm{CO}_{2}$ recovered in a glass ampoule with its corresponding theoretical amount of $\mathrm{CH}_{4}$ injected 
Table 1 Quality assurance parameters of the Methane Preconcentration and Purification Setup (MPPS), with average uncertainty $(1 \sigma)$ and standard deviation (Std dev) of all measurements (both calculated referring to a single analysis). See Supplementary Materials for detailed results.

\begin{tabular}{lcccr}
\hline Quality parameter & Value & Uncertainty & Std dev & $n$ \\
\hline Constant contamination mass $(\mu \mathrm{g} \mathrm{C})$ & 0.35 & 0.10 & - & 22 \\
Constant contamination $\mathrm{F}^{14} \mathrm{C}$ & 0.35 & 0.18 & - & 22 \\
Cross contamination $(\%)$ & 0.4 & 0.2 & - & 2 \\
Repeatability* $\left(\mathrm{F}^{14} \mathrm{C}\right)$ & 1.539 & 0.012 & 0.010 & 6 \\
Accuracy\#: measurement $\left(\mathrm{F}^{14} \mathrm{C}\right)$ & 1.018 & 0.008 & 0.009 & 3 \\
Accuracy: reference value $\left(\mathrm{F}^{14} \mathrm{C}\right)$ & 1.024 & 0.003 & - & - \\
MPPS yield $(\%)$ & 101.2 & 1.4 & - & 13 \\
\hline
\end{tabular}

*Determined from repeated analysis of $60 \mathrm{~L}$ of the pressurized air sample.

\#Determined from repeated analysis of the modern methane standard.

into the PRECON (see Table 1). The samples used for this evaluation were collected in aluminum bags at the Beromünster tall tower, Switzerland, as described by Berhanu et al. (2017). The yield of the MPPS is $101.2 \pm 1.4 \%$, indicating a quantitative recovery of $\mathrm{CH}_{4}$ during the preconcentration and purification steps.

The chromatographic purification of $\mathrm{CH}_{4}$ after preconcentration is an essential step, as it guarantees the reliability of the ${ }^{14} \mathrm{C}$ results. Such an approach has been previously employed by some other groups (e.g. Wahlen et al. 1989; Eisma et al. 1994). However, their systems were used for the purification of much larger air volumes and thus required more traps and a long and labor-intensive procedure limiting their throughput. The simplified preconcentration line presented here drastically reduces the sample preparation time for a ${ }^{14} \mathrm{CH}_{4}$ measurement, as three samples can be readily prepared within a working day. Hence, the MPPS is suited to the monitoring of atmospheric ${ }^{14} \mathrm{CH}_{4}$.

\section{Versatility}

According to the research strategy depicted in Figure 1, the two systems presented in this work can be adapted to handle $\mathrm{CH}_{4}$ collected from many diverse environments (e.g. aquatic, wetland, marine etc.), where $\mathrm{CH}_{4}$ concentrations can be much higher than in atmospheric air. As methanogenesis is often intense in the carbon-rich sediments at the bottom of some lakes and ponds, typical concentrations in the samples collected can be high enough so that a few milliliters contain enough $\mathrm{CH}_{4}$ for a radiocarbon analysis (Rinta et al. 2015). If so, the sample does not require preconcentration and the PURIF can be used alone as it can handle direct injections of gas mixtures up to $10 \mathrm{~mL}$.

For intermediate concentration methane sources, such as arctic lakes or peatlands, gas samples are usually extracted with headspace techniques (Walter et al. 2008; Garnett et al. 2011). A methane ${ }^{14} \mathrm{C}$ analysis of such samples often involves the extraction from gas samples of a few hundred milliliters. In this case, using the whole PRECON might be an overkill; hence, it may be possible to adapt the PRECON to use the second preconcentration step with $\mathrm{CT} 2$ alone before performing the $\mathrm{CH}_{4}$ purification.

Finally, $\mathrm{CH}_{4}$ dissolved in low concentration waters can be extracted with membrane contactors (Matsumoto et al. 2013; Sparrow and Kessler 2017), resulting in extracted gas volumes similar 
to the ones required for atmospheric air sampling. Thus, these samples can be handled as the atmospheric air samples by combination of the whole PRECON and the PURIF.

\section{CONCLUSION}

A new methane preconcentration and purification setup was developed for the preparation of atmospheric $\mathrm{CH}_{4}$ samples for ${ }^{14} \mathrm{C}$ measurements. The system requires only $\sim 50 \mathrm{~L}$ of atmospheric air, which can be collected in an aluminum bag or pressurized in a gas bottle. A preparative gas chromatography technique is used for $\mathrm{CH}_{4}$ isolation, which confirms that methane has been successfully separated from any other carbon-containing gases such as $\mathrm{CO}$ or $\mathrm{CO}_{2}$ that could dramatically bias the ${ }^{14} \mathrm{CH}_{4}$ results. A procedural blank of $0.35 \pm 0.10 \mu \mathrm{g} \mathrm{C}$ with an $\mathrm{F}^{14} \mathrm{C}$ of $0.35 \pm 0.18$ was determined, which is low compared to the typical amounts of $\mathrm{CH}_{4}$ purified and measured. Methane is quantitatively extracted from the original air sample and isolated as pure $\mathrm{CH}_{4}$ for the AMS ${ }^{14} \mathrm{C}$ measurement, which shows a good accuracy and repeatability. The system is therefore well suited to the radiocarbon analysis of atmospheric $\mathrm{CH}_{4}$. Since methane is not combusted before purification, $\mathrm{CH}_{4}$ aliquots can be collected for stable isotope measurements. Combined with ${ }^{14} \mathrm{C}$ results, they should provide complementary information.

\section{ACKNOWLEDGMENTS}

We are grateful to the funding of the Dr. Alfred Bretscher Scholarship. Carina van der Veen and Henk Snellen (IMAU, Utrecht) assisted during the early steps of the setup development. Markus Leuenberger, Thomas Wagner and Peter Dürring (Climate and Environmental Physics, University of Bern) provided the methane modern standard, the air samples from Beromünster, the PICARRO and the pressurized air bottle. We further thank Robert Eichler (Paul Scherrer Institute) for the oven furnace and Gary Salazar for the assistance with the MICADAS and the evaluation of the data.

\section{SUPPLEMENTARY MATERIAL}

To view supplementary material for this article, please visit https://doi.org/10.1017/RDC.2019.76

\section{REFERENCES}

Bergamaschi P, Brenninkmeijer CAM, Hahn M, Röckmann T, Scharffe DH, Crutzen PJ, Elansky NF, Belikov IB, Trivett NBA, Worthy DEJ. 1998. Isotope analysis based source identification for atmospheric $\mathrm{CH}_{4}$ and $\mathrm{CO}$ sampled across Russia using the Trans-Siberian railroad. Journal of Geophysical Research: Atmospheres 103(D7):8227-8235. doi: 10.1029/ 97JD03738.

Berhanu TA, Szidat S, Brunner D, Satar E, Schanda R, Nyfeler P, Battaglia M, Steinbacher M, Hammer S, Leuenberger M. 2017. Estimation of the fossil fuel component in atmospheric $\mathrm{CO}_{2}$ based on radiocarbon measurements at the Beromünster tall tower, Switzerland. Atmospheric Chemistry and Physics 17(17):10753-10766. doi: 10.5194/ acp-17-10753-2017.
Bock M, Schmitt J, Behrens M, Möller L, Schneider R, Sapart C, Fischer H. 2010. A gas chromatography/ pyrolysis/isotope ratio mass spectrometry system for high-precision $\delta \mathrm{D}$ measurements of atmospheric methane extracted from ice cores. Rapid Communications in Mass Spectrometry 24(5):621-633. doi: 10.1002/rcm.4429.

Bousquet P, Ciais P, Miller JB, Dlugokencky EJ, Hauglustaine DA, Prigent C, der Werf GRV, Peylin P, Brunke E-G, Carouge C, et al. 2006. Contribution of anthropogenic and natural sources to atmospheric methane variability. Nature 443:439-443. doi: 10.1038/nature05132.

Brass M, Röckmann T. 2010. Continuous-flow isotope ratio mass spectrometry method for carbon and hydrogen isotope measurements on atmospheric methane. Atmospheric Measure- 
ment Techniques 3(6):1707-1721. doi: 10.5194/ amt-3-1707-2010.

Bräunlich M. 2000. Study of atmospheric carbon monoxide and methane using isotopic analysis [dissertation]. Heidelberg, Germany: University of Heidelberg.

Brenninkmeijer CAM. 1991. Robust, high-efficiency, high-capacity cryogenic trap. Analytical Chemistry 63(D6):1182-1184.

Brenninkmeijer CAM. 1993. Measurement of the abundance of ${ }^{14} \mathrm{CO}$ in the atmosphere and the ${ }^{13} \mathrm{C} /{ }^{12} \mathrm{C}$ and ${ }^{18} \mathrm{O} /{ }^{16} \mathrm{O}$ ratio of atmospheric $\mathrm{CO}$ with applications in New Zealand and Antarctica. Journal of Geophysical Research 98(D6):10595-10614. doi: 10.1029/93JD00587.

Brenninkmeijer CAM, Röckmann T. 1996. Russian doll type cryogenic traps: improved design and isotope separation effects. Analytical Chemistry 68(17):3050-3053. doi: 10.1021/ac960208w.

Brown TA, Southon JR. 1997. Corrections for contamination background in AMS ${ }^{14} \mathrm{C}$ measurements. Nuclear Instruments and Methods in Physics Research B 123(1-4):208213. doi: 10.1016/S0168-583X(96)00676-3.

Dean JF, Middelburg JJ, Röckmann T, Aerts R, Blauw LG, Egger M, Jetten MSM, de Jong AEE, Meisel $\mathrm{OH}$, Rasigraf O, et al. 2018. Methane Feedbacks to the Global Climate System in a Warmer World. Reviews of Geophysics 56(1):207-250. doi: 10.1002/2017RG000559.

Dlugokencky EJ, Nisbet EG, Fisher R, Lowry D. 2011. Global atmospheric methane: budget, changes and dangers. Philos. Trans. R. Soc. London Ser. A 369(1943):2058-72. doi: 10.1098/ rsta.2010.0341.

Dumke I, Faber E, Poggenburg J. 1989. Determination of stable carbon and hydrogen isotopes of light hydrocarbons. Analytical Chemistry 61(19):214954. doi: 10.1021/ac00194a007.

Eisma R, van der Borg K, de Jong AFM, Kieskamp WM, Veltkamp AC. 1994. Measurements of the ${ }^{14} \mathrm{C}$ content of atmospheric methane in The Netherlands to determine the regional emissions of ${ }^{14} \mathrm{CH}_{4}$. Nuclear Instruments and Methods in Physics Research B 92(1-4):410-412. doi: 10. 1016/0168-583X(94)96044-5.

Garnett MH, Hardie SML, Murray C. 2011. Radiocarbon and stable carbon analysis of dissolved methane and carbon dioxide from the profile of a raised peat bog. Radiocarbon 53(1):71-83. doi: 10.1017/S0033822200034366.

Garnett MH, Murray C, Gulliver P, Ascough PL. 2019. Radiocarbon analysis of methane at the NERC Radiocarbon Facility (East Kilbride). Radiocarbon. doi: 10.1017/RDC.2019.3.

Hiller RV, Bretscher D, DelSontro T, Diem T, Eugster W, Henneberger R, Hobi S, Hodson E, Imer D, Kreuzer M, et al. 2014. Anthropogenic and natural methane fluxes in Switzerland synthesized within a spatially explicit inventory. Biogeosciences 11(7):1941-59. doi: 10.5194/bg11-1941-2014.

Jacob DJ, Turner AJ, Maasakkers JD, Sheng J, Sun K, Liu X, Chance K, Aben I, McKeever J, Frankenberg C. 2016. Satellite observations of atmospheric methane and their value for quantifying methane emissions. Atmospheric Chemistry and Physics 16(22):14371-14396. doi: 10.5194/acp-16-14371-2016.

Kessler JD, Reeburgh WS. 2005. Preparation of natural methane samples for stable isotope and radiocarbon analysis. Limnology and Oceanography: Methods 3(9):408-418. doi: 10. 4319/lom.2005.3.408.

Lassey KR, Lowe DC, Smith AM. 2007. The atmospheric cycling of radiomethane and the "fossil fraction" of the methane source. Atmospheric Chemistry and Physics 7(8):21412149. doi: 10.5194/acp-7-2141-2007.

Loosli HH, Heimann M, Oeschger H. 1980. Lowlevel gas proportional counting in an underground laboratory. Radiocarbon 22(2):461-9. doi: 10.1017/S0033822200009772.

Lowe DC, Brenninkmeijer CAM, Tyler SC, Dlugkencky EJ. 1991. Determination of the isotopic composition of atmospheric methane and its application in the Antarctic. Journal of Geophysical Research 96(D8):15,455-15,467. doi: 10.1029/91JD01119.

Matsumoto T, Han L-F, Jaklitsch M, Aggarwal PK. 2013. A portable membrane contactor sampler for analysis of noble gases in groundwater. Groundwater 51(3):461-468. doi: 10.1111/j. 1745-6584.2012.00983.x.

McIntyre CP, McNichol AP, Roberts ML, Seewald JS, von Reden KF, Jenkins WJ. 2013. Improved precision of radiocarbon measurements for $\mathrm{CH}_{4}$ and $\mathrm{CO}_{2}$ using $\mathrm{GC}$ and continuous-flow AMS achieved by summation of repeated injections. Radiocarbon 55(2):677685. doi: 10.1017/S0033822200057830.

Miller JB, Mack KA, Dissly R, White JWC, Dlugokencky EJ, Tans PP. 2002. Development of analytical methods and measurements of ${ }^{13} \mathrm{C} /{ }^{12} \mathrm{C}$ in atmospheric $\mathrm{CH}_{4}$ from the NOAA Climate Monitoring and Diagnostics Laboratory Global Air Sampling Network. Journal of Geophysical Research 107(D13):4178. doi: 10.1029/ 2001JD000630.

Němec M, Wacker L, Gäggeler H. 2010. Optimization of the graphitization process at AGE-1. Radiocarbon 52(2-3):1380-1393. doi: 10.1017/S0033822200046464.

Nisbet E, Weiss R. 2010. Top-down versus bottomup. Science 28(5983):1241-1243. doi: 10.1126/ science. 1189936.

Pack MA, Xu X, Lupascu M, Kessler JD, Czimczik CI. 2015. A rapid method for preparing low 
volume $\mathrm{CH}_{4}$ and $\mathrm{CO}_{2}$ gas samples for ${ }^{14} \mathrm{C}$ AMS analysis. Organic Geochemistry 78:89-98. doi: 10.1016/j.orggeochem.2014.10.010.

Palonen V, Uusitalo J, Seppälä E, Oinonen M. 2017. A portable methane sampling system for radiocarbon-based bioportion measurements and environmental $\mathrm{CH}_{4}$ sourcing studies. Review of Scientific Instruments 88:075102. doi: 10.1063/1.4993920.

Petrenko VV, Smith AM, Brailsford G, Riedel K, Hua Q, Lowe D, Severinghaus JP, Levchenko V, Bromley T, Moss R, et al. 2008. A new method for ${ }^{14} \mathrm{C}$ analyzing of methane in ancient air extracted from glacial ice. Radiocarbon 50(1):53-73. doi: 10.1017/S0033822200043368.

Petrenko VV, Smith AM, Schaefer H, Riedel K, Brook E, Baggenstos D, Harth C, Hua Q, Buizert C, Schilt A, et al. 2017. Minimal geological methane emissions during the Younger DryasPreboreal abrupt warming event. Nature 548(7668):443-6. doi: 10.1038/nature23316.

Quay P, Stutsman J, Wilbur D, Snover A, Dlugokencky E, Brown T. 1999. The isotopic composition of atmospheric methane. Global Biogeochemical 13(2):445-461. doi: 10.1029/ 1998GB900006.

Rinta P, Bastviken D, van Hardenbroek M, Kankaala P, Leuenberger M, Schilder J, Stötter T, Heiri O. 2015. An inter-regional assessment of concentrations and $\delta^{13} \mathrm{C}$ values of methane and dissolved inorganic carbon in small European lakes. Aquatic Sciences 77(4):667680. doi: 10.1007/s00027-015-0410-y.

Röckmann T. 1998. Measurement and interpretation of ${ }^{13} \mathrm{C},{ }^{14} \mathrm{C},{ }^{17} \mathrm{O}$ and ${ }^{18} \mathrm{O}$ variations in atmospheric carbon monoxide [dissertation]. Heidelberg, Germany: University of Heidelberg.

Salazar G, Zhang YL, Agrios K, Szidat S. 2015. Development of a method for fast and automatic radiocarbon measurement of aerosol samples by online coupling of an elemental analyzer with a MICADAS AMS. Nuclear Instruments and Methods in Physics Research B 361:163-167. doi: 10.1016/j.nimb.2015.03.051.

Sapart CJ, Shakhova N, Semiletov I, Jansen J, Szidat S, Kosmach D, Dudarev O, van der Veen C, Egger M, Sergienko V, et al. 2017. The origin of methane in the East Siberian Arctic Shelf unraveled with triple isotope analysis. Biogeosciences 14(9):2283-2292. doi: 10.5194/bg2016-367.

Saunois M, Bousquet P, Poulter B, Peregon A, Ciais P, Canadell JG, Dlugokencky EJ, Etiope G, Bastviken D, Houweling S, et al. 2016. The global methane budget 2000-2012. Earth System Science Data 8(2):697-751. doi: 10.5194/ essd-8-697-2016.

Schmitt J, Seth B, Bock M, van der Veen C, Möller L, Sapart CJ, Prokopiou M, Sowers T, Röckmann T, Fischer H. 2013. On the interference of $\mathrm{Kr}$ during carbon isotope analysis of methane using continuous-flow combustion-isotope ratio mass spectrometry. Atmospheric Measurement Techniques 6(5):1425-45. doi: 10.5194/amt-61425-2013.

Sparrow KJ, Kessler JD. 2017. Efficient collection and preparation of methane from low concentration waters for natural abundance radiocarbon analysis. Limnology and Oceanography: Methods 15(7):601-617. doi: 10. 1002/lom3.10184.

Stolper DA, Martini AM, Clog M, Douglas PM, Shusta SS, Valentine DL, Sessions AL, Eiler JM. 2015. Distinguishing and understanding thermogenic and biogenic sources of methane using multiply substituted isotopologues. Geochimica et Cosmochimica Acta 161: 219-247. doi: 10.1016/j.gca.2015.04.015.

Szidat S, Jenk TM, Gäggeler HW, Synal H-A, Hajdas I, Bonani G, Saurer M. 2004. THEODORE, a two-step heating system for the EC/OC determination of radiocarbon $\left({ }^{14} \mathrm{C}\right)$ in the environment. Nuclear Instruments and Methods in Physics Research B 223-224:829-836. doi: 10.1016/j.nimb.2004.04.153.

Szidat S, Salazar G, Vogel E, Battaglia M, Wacker L, Synal H-A, Türler A. $2014 .{ }^{14} \mathrm{C}$ analysis and sample preparation at the new Bern Laboratory for the Analysis of Radiocarbon with AMS (LARA). Radiocarbon 56(2):561-566. doi: 10. 2458/56.17457.

Townsend-Small A, Tyler SC, Pataki DE, Xu X, Christensen LE. 2012. Isotopic measurements of atmospheric methane in Los Angeles, California, USA: Influence of "fugitive" fossil fuel emissions. Journal of Geophysical Research 117:D07308. doi: 10.1029/2011JD016826.

Wahlen M, Tanaka N, Henry R, Deck B, Zeglen J, Vogel JS, Southon J, Shemesh A, Fairbanks R, Broecker W. 1989. Carbon-14 in methane sources and in atmospheric methane: the contribution from fossil carbon. Science 245(4915):286-290. doi: 10.1126/science.245. 4915.286.

Walter KM, Zimov SA, Chanton JP, Verbyla D, Chapin III FS. 2006. Methane bubbling from Siberian thaw lakes as a positive feedback to climate warming. Nature 443(7107):71-75. doi: 10.1038/nature05040.

Walter KM, Chanton JP, Chapin III FS, Schuur EAG, Zimov SA. 2008. Methane production and bubble emissions from arctic lakes: Isotopic implications for source pathways and ages. Journal of Geophysical Research 113:G00A08. doi: 10.1029/2007JG000569.

Zimov SA, Voropaev YV, Semiletov IP, Davidov SP, Prosiannikov SF, Chapin III FS, Chapin MC, Trumbore S, Tyler S. 1997. North Siberian lakes: a methane source fueled by Pleistocene carbon. Science 277(5827):800-802. doi: 10.1126/ science. 277.5327 .800 . 